\title{
O Brasil no espelho de Amaterasu: O Japão de Aluísio Azevedo
}

Marcel Vejmelka ${ }^{1}$

De 1897 a 1899, Aluísio Azevedo esteve como vice-cônsul em Yokohama. Nesses anos concebeu e esboçou um livro sobre a cultura e sociedade japonesas no passado e no presente, do qual chegou a escrever somente a primeira parte, dedicada à História do Japão. Este fragmento, publicado em 1984 por Luiz Dantas, possibilita analisar a visão de Azevedo da nação e cultura japonesas, a serem compreendidas dentro do contexto histórico do fim do século XIX e em relação com as conflitividades internas da nação e cultura brasileiras como Azevedo as tratou nos seus romances naturalistas.

\section{Aluísio Azevedo, naturalista}

Aluísio Azevedo, nascido em 1857 em São Luís do Maranhão, é visto como o primeiro e mais importante representante do Naturalismo na história literária brasileira. Inspirado por Émile Zola, mas também pelo português Eça de Queiroz, iniciou a vertente brasileira desse programa literário em 1881 com o romance $O$ mulato, onde criticou e denunciou as injustiças da escravidão como também o racismo 'estrutural' da sociedade brasileira. ${ }^{2}$ A percepção da dimensão social do racismo no romance continua atual e reveladora, mostrando que a concreta cor da pele do 'mulato' não é tão relevante como a sua descendência enquanto 'filho de uma escrava', um fato que nunca consegue apagar

\footnotetext{
${ }^{1}$ Doutor em Estudos Latino-americanos, professor de Espanhol e Português, Faculdade de Tradução, Linguística e Estudos Culturais (FTSK) da Universidade Johannes-Gutenberg de Mainz, em Germersheim, Alemanha.

${ }^{2}$ A mais abrangente e profunda biografia literária de Azevedo continua sendo a de Jean-Yves Mérian (1988).
}

Brasiliana - Journal for Brazilian Studies. Vol. 2, n.2 (Nov 2013). ISSN 2245-4373. 
e que determina o seu destino. No romance, Azevedo combina a sua crítica da hipocrisia da classe dominante no norte do Brasil - os tradicionais latifundistas, os comerciantes portugueses, o clero - com descrições costumbristas da vida social e cultural em São Luís (cf. Azevedo, 1970).

Já o título de seu romance mais conhecido, O cortiço, de 1890, aponta para uma forma específica de moradia para os milhares de operários, braceiros e lavandeiras, também de criminosos de pequeno porte e de prostitutas, imigrantes portugueses e brasileiros oriundos do interior e do nordeste do país, no Rio de Janeiro do fim do século XIX e início do século XX. Na capital brasileira, a perspetiva do escritor se vai ampliando para as questões e os conflitos sociais vigentes na formação nacional do país (Azevedo, 1983). Num terreno atrás da sua loja, um pequeno comerciante português no bairro de Botafogo constrói uma série de barracos ou casas, uma cidade em miniatura para os pobres, um microcosmo da marginalidade social, que se vai reproduzindo e repetindo inúmeras vezes pela cidade e que, na análise de Antonio Candido, constitui uma "alegoria antinaturalista do Brasil" (Candido, 2004: 116). É nesse cenário que Azevedo retrata e estuda as tentativas, afinal todas frustradas, dos moradores de sair do círculo vicioso da miséria e ascender socialmente.

Dentro da preocupação fundamental pela nacionalidade brasileira ou pelo Brasil enquanto nação moderna, Azevedo aplica o sistema do naturalismo, com suas contradições entre o determinismo social e o biologismo, à realidade brasileira. O aspecto biológico entra na categorização dos personagens segundo as diferentes 'raças' que compõem o povo brasileiro, com nítida distinção entre o elemento afrobrasileiro e os europeus de imigração recente. Esta dimensão é superposta pela questão das classes sociais, onde a elite lusobrasileira é confrontada com a vasta camada popular, sendo esta última diferenciada internamente com os seus conflitos entre negros e mestiços e imigrantes portugueses:

Brasiliana - Journal for Brazilian Studies. Vol. 2, n.2 (Nov 2013). ISSN 2245-4373. 
“Está em discussão toda a constituição da nação brasileira, através da miscigenação racial e cultural. Ao longo do romance, eivado dos preconceitos da época, vão aparecendo os diferentes modos de adaptação do português ao Brasil, além da luta dos negros e, especialmente, dos mestiços pela sobrevivência. Desse convívio de tipos vai se fazendo o romance, como ia se fazendo a nação." (Dalcastagnè, 2001: 486)

Enquanto representante do naturalismo no Brasil, Aluísio Azevedo não espaca das contradições e aporias caraterísticas do movimento literário como um todo, mas dadas as circunstâncias históricas, sociais e culturais, no Brasil essas conflitividades internas do naturalismo ganham urgência particular, por exemplo em diálogo com os discursos raciais e racistas das elites nacionais e no que diz respeito à auto-imagem da nação brasileira em termos sócioculturais. Entretante, esta problemática do escritor naturalista brasileiro não está em foco aqui. O que interessa é reconstruir e analisar como Aluísio Azevedo - justamente com esta 'bagagem' naturalista - viu, interpretou e representou a história e a realidade sóciocultural de um país aparentemente tão diferente do Brasil: o Japão da virada do século XIX para o XX.

\section{As relações nipo-brasileiras}

Aluísio Azevedo figura entre os primeiros e poucos escritores brasileiros que tiveram a possibilidade de exercer de fato a escrita como profissão. Mesmo assim, sofreu com as fraquezas estruturais do sistema literário (cf. Candido, 2000) no seu tempo, o que resultava principalmente numa permanente falta de recursos financeiros, um fato que 
ele lamentava frequentemente e que tentou resolver tornando-se funcionário público. Em 1895 conseguiu, com a intervenção do colega e amigo Graça Aranha, entrar no serviço diplomático da jovem República Brasileira. Mas a carreira diplomática o obrigou a abandonar a literatura. Consequentemente, quase todos os estudos biográficos sobre Aluísio Azevedo consideram o romance Livro de uma sogra, de 1895, o ponto final da sua obra.

Entretanto, essa afirmação não é perfeitamente correta. Pois em 1897 Azevedo foi nomeado vice-cônsul em Yokohama, depois do início das relações diplomáticas entre o Brasil e o Japão em 1895, com a assinatura, em Paris, do Tratado de Amizade, Comêrcio e Navegação (cf. Ninomiya, 1995/96). Este tratado bilateral se insere nos tratados assinados entre o Japão e o Peru, em 1873, e com o México, em 1888, para contrabalançar os acordos comerciais desfavoráveis, assinados a partir de 1858 sob pressão diplomática e militar dos Estados Unidos e vários países europeus.

Outra intenção do Império Japonês era resolver, através da emigração subsidiada, o problema demográfico que surgira com a modernização massiva do país na segunda metade do século XIX. ${ }^{3}$ Há poucas informações sobre as tarefas de Azevedo como diplomata no Japão, mas do pouco que consta se sabe que exerceu o cargo de "auxiliar" ou "agente de imigração" - cargo, aliás, que já exercera na sua primeira missão em Vigo, na Espanha. O objetivo de seu trabalho era, portanto, incentivar e organizar a imigração para o Brasil, fornecendo mão-de-obra barata para satisfazer a demanda surgida com a Abolição da escravatura em 1888 e a subsequente concentração da economia nacional na área das exportações agrícolas.

\footnotetext{
${ }^{3}$ Hideki Yamamura (1996: 137) anota para o período entre 1875 e 1900 um crescimento demográfico de 30 milhões para 45 milhões de habitantes. Ao mesmo tempo constata, porém, que o número total dos japoneses emigrados entre o final do século XIX e meados do século XX - apenas cerca de um milhão - não contribuiu de modo relevante para o intencionado controle do crescimento populacional.
}

Brasiliana - Journal for Brazilian Studies. Vol. 2, n.2 (Nov 2013). ISSN 2245-4373. 
Este aspecto aponta para o processo da imigração japonesa para o Brasil, que se iniciaria em 1908 e levaria, ao total, cerca de 250.000 japoneses a tentar e encontrar uma nova vida no país sul-americano. Estes trabalhavam inicialmente nas plantações de café e como pequenos agricultores, principalmente nos estados de São Paulo e Paraná. Mais tarde migraram para as cidades e foram se integrando cada vez mais na sociedade e cultura brasileiras. Hoje, cerca de dois milhões de nikkei - brasileiros de origem japonesa - vivem no Brasil, e o bairro da Liberdade no centro de São Paulo, com seus cerca de 300.000 de habitantes, constitui ainda a maior comunidade japonesa fora do Japão.

A pesquisa a respeito da cultura nikkei no Brasil ainda constitui uma disciplina jovem, longe de ter explorado por completo o seu objeto. Isso vale sobretudo em relação aos aspetos interculturais e transculturais da presença japonesa no país, uma temática pendente depois da documentação histórica da emigração e imigração japonesa, já bastante abrangente. Também vale para os poucos documentos literários da cultura nikkei, que por enquanto se limitam à memória do Japão e/ou dos primeiros anos dos imigrantes no Brasil. ${ }^{4} \mathrm{E}$ ainda mais vale para o fenômeno mais recente no âmbito dessas relações, a migração ou remigração, inicialmente temporária, de nipo-japoneses para o Japão desde o início dos anos 80, os chamados dekassegui, dos quais surgiram comunidades nipo-brasileiras (até hoje cerca de 300.000 pessoas) radicadas no país de seus avôs e bisavôs. ${ }^{5}$ Este breve resumo da evolução histórica, que se originou do

\footnotetext{
${ }^{4}$ Tomoo Handa (1987) oferece um amplo panorama histórico da imigração japonesa para o Brasil e de seu desenvolvimento sócio-cultural até os anos 80 do século XX. Diferentes aspectos da presença japonesa na sociedade e cultura do Brasil são analisados na coletâneas de Hiroshi Saito (1980), da Sociedade Brasileira de Cultura Japonesa (1992), e mais recentemente no volume organizado por Maria Luiza Tucci Carneiro e Márcia Yumi Takeuchi (2010). O jardim japonês, de Ana França Suzuki (1986), é considerado o primeiro 'romance nikkei' no Brasil, mas foi escrito pela esposa brasileira de um nipo-brasileiro. A temática da integração e da 'nova vida' no Brasil também é tratada em Sonhos bloqueados de Laura Honda-Hasegawa (1991). No séclo XXI, esta temática ganhou novo destaque literário com o romance Nihonjin de Óscar Nakasato (2011).

${ }^{5}$ Panoramas dessa evolução mais recente se encontra em Elisa Sasaki (2006), Angelo Ishi (2003) e Takeyuki Tsuda (2003). Em Sonhos que de cá segui, um relato situado entre a ficção e a reportagem, Sílvio Sam (1997) relata um destino de (re)migrante; em Circle K Cycles, a escritora estado-unidense de origem japonesa Karen Tei Yamashita (2001) amplia a perspectiva para a dimensão hemisférica das Américas e retrata os processos transculturais experimentados pelos dekasseguis brasileiros.
}

Brasiliana - Journal for Brazilian Studies. Vol. 2, n.2 (Nov 2013). ISSN 2245-4373. 
momento aqui analisado, pretende somente esboçar a dimensão das relações nipobrasileiras que não poderão ser desconsideradas neste contexto. A presença de Aluísio Azevedo no Japão e o que ele escreveu sobre o país se encontram, portanto, no início desses processos históricos.

Com isso, voltamos ao ano de 1897. Azevedo acompanhava então a fase da modernização e transformação radical do Estado japonês, de sua sociedade e cultura durante a época Meiji (1868-1912), iniciada após lutas internas pelo poder causadas pela abertura do país, forçada pelos Estados Unidos em 1853/54. Em 1867 o shogunato (bakufu) foi abolido, em 1868 o sistema político em torno à figura do Imperador (tennō) foi reestruturado, e em 1889, finalmente, o Japão se contituiu como Estado moderno com uma constituição fortemente influenciada pelo modelo prussiano. É fácil imaginar que as transformações culturais causadas por este processo motivaram Aluísio Azevedo a escrever um livro sobre o Japão.

\section{Aluísio Azevedo como intérprete da história do Japão}

Ao todo e com duas curtas interrupções, Aluísio Azevedo permaneceu dois anos como vice-cônsul em Yokohama (1897-99). Durante esse período, trabalhava no seu projeto de livro sobre a cultura e sociedade japonesa no passado e no presente. O seu biógrafo Jean-Yves Mérian formula possíveis motivações para esse retorno à escrita literária:

“Aluísio Azevedo não perdera nem o gosto nem a vontade de escrever, como haviam pretendido os críticos mencionados acima. Havia faltado ao romancista até então um tema que o apaixonasse e o tempo para 
criar. No Japão, as duas condições estavam reunidas. Ele resolveu escrever 'O Japão como ele é'. Não se tratava de uma ficção romanesca, mas sim de um estudo, de uma espécie de grande reportagem, sobre os aspectos mais diversos do Japão: história, hábitos, costumes, vida religiosa, intelectual e artística. O sentido de observação, de pesquisa sociológica de que dera provas na concepção de suas obras naturalistas, despertou novamente." (Mérian, 1988: 609)

Este livro, do qual se afirma também que possivelmente iria receber o título de "Agonia de uma raça" (Dantas, 1984a: 36), foi concebido e escrito na íntegra, porém Azevedo não chegou a revisá-lo e retrabalhá-lo definitivamente, e assim ficou inédito em tempo de vida do autor. Conforme os dados oferecidos por Mérian e Dantas, o manuscrito completo se encontra no acervo pessoal do escritor em Buenos Aires, infelizmente inacessível ao público.

Uma primeira parte do manuscrito, entretanto, que pode ser considerada definitiva, iria ser publicada ainda durante a estada de Azevedo no Japão, numa edição de luxo, ricamente ilustrada, no Rio de Janeiro (Mérian, 1988: 610). Este projeto ficou impedido devido a uma confusão financeira (Dantas, 1984a: 13), depois o projeto completo foi abandonado. Um motivo foi a involuntária recolocação de Aluísio Azevedo para a Argentina, outro que possivelmente perdeu o entusiasmo para terminar o projeto depois de não ter conseguido publicar a primeira parte. Em 1980, Dantas organizou a mencionada primeira parte do texto, guardada nos arquivos da Academia Brasileira de Letras, instituição da qual Azevedo era membro fundador desde 1897, e a publicou em 1984 com o título de O Japão, acompanhada por um apêndice com notas e comentários críticos (Azevedo, 1984).

Brasiliana - Journal for Brazilian Studies. Vol. 2, n.2 (Nov 2013). ISSN 2245-4373. 
Dantas explica que assim queria possibilitar duas formas de leitura: a leitura isolada do texto azevediano, com os efeitos imediatos de seus recursos literários, e outra combinada com os comentários, para corrigir as inexatidões históricas, preencher lacunas e esclarecer o contexto geral. Nisso, Dantas tem o cuidado de sempre contemplar os erros, malentendidos e informações faltantes de Azevedo em função do próprio texto: "Muito mais fundamental que exatidão do fato histórico narrado, parece a atitude do observador, a escolha que faz" (Dantas, 1984a: 31), escreve Dantas na introdução, e afirma ainda: "Aluísio Azevedo, escrevendo sobre o Japão, permanece o romancista, cuja primeira preocupação é a literária." (Dantas, 1984a: 33)

\section{O Mito e a Dinâmica Cultural}

Em O Japão não se cumprem possíveis expetativas motivadas pelos temas e objetos da obra literária de Azevedo. O livro não retrata a vida do povo simples, não fornece - ao contrário da intensidade do seu contemporâneo português no Japão, Wenceslau de Moraes $^{6}$ - observações concretas e detalhadas do cotidiano e da cultura japonesa. O texto relata em cinco capítulos, que eu vou comentar a seguir, a História do Japão até pouco antes do momento histórico em que escreve Azevedo. O próprio autor explica que quer assim tornar acessíveis aos países ocidentais as fontes sobre o passado do Japão, para que providenciem a luz necessária para a contemplação da modernização do país na época:

\footnotetext{
${ }^{6}$ A respeito da vida e obra de Wenceslau de Moraes, cf. Feldmann (1992). De maneira fundamental, há uma proximdade remarcável entre $O$ Japão de Azevedo e Dai Nippon. O Grande Japão de Wenceslau de Moraes (Moraes 1972), publicado em 1897, no que diz respeito ao conteúdo e à estrutura dos dois livros. A comparação das duas obras mereceria um estudo mais detido.
}

Brasiliana - Journal for Brazilian Studies. Vol. 2, n.2 (Nov 2013). ISSN 2245-4373. 
“[...] dar exata notícia do que foi aquele passado, outrora tão misterioso e sem fundo, e do que vem a ser ao justo essa famosa revolução que num momento de frenesi histórico derrocou, em nossos dias, um mundo insondável de tradições acumuladas durante vinte e dois séculos de sigilo nacional." (Azevedo, 1984: 41)

As fontes que Azevedo consultou são, segundo Dantas, em primeiro lugar o Kojiki, compilado em 712, na tradução para o inglês por Basil Hall Chamberlain, de 1833, e o Nihongi ou Nihonshoki (Crônicas do Japão, de 720) na tradução inglesa de William George Aston, de 1896. Azevedo teve acesso a essas obras principalmente através de sua fonte mais importante, Le Japon de nos jours et les Echelles de l'Extrême Orient, escrito por Georges Bousquet em 1877. Bousquet foi consultor jurídico do Governo japonês entre 1872 e 1876, Azevedo adquiriu o livro em Paris, a caminho do Japão (Dantas, 1984b: 143). Já nesse momento se evidencia a ampla e complexa rede dos japonistas europeus, pois o japanólogo Chamberlain e a sua tradução do Kojiki constam também entre as fontes principais de Lafcadio Hearn, que dedicou a sua obra Glimpses of Unfamiliar Japan (Hearn, 2005), publicada em 1894, a aquele. E como Wenceslau de Moraes, Azevedo também lera com entusiasmo os estudos de Edmond de Goncourt sobre as estampas de Utamaro (Outamaro - le peintre de maisons vertes) e Hokusai (Hokousaï. L'art japonais au XVIIème siècle), publicadas em 1891 e 1896, respectivamente, as primeiras fontes do Japonismo europeu (Dantas, 1984b: 185).

O próprio Azevedo explica que o seu texto se situa entre os gêneros tradicionais, que não representa um estudo historiográfico nem um relato de viagens ou até um romance, mas que seria uma "singela obra de impressões pessoais" (Azevedo, 1984: 41) combinadas com a dimensão literária, inscrita já na História do Japão com a sua auto- 
imagem; uma História que começaria, conforme Azevedo, com o mito, para no presente desembocar na moderna tecnocracia e burocracia:

[...] pois começa poeticamente por uma lenda maravilhosa e risonha, palpitante de quimeras e ficções divinas, a acaba na mais engravatada e burocrática monarquia constitucional, com os seus ministérios de casaca bordada, com as suas secretarias de Estado e os seus competentes amanuenses de calças puídas, a até, acreditai se quiserdes!, com o pálido bacharel apenas desabrochado da academia sem outro ideal na vida além de apanhar por empenho qualquer emprego público. (Azevedo, 1984: 41)

No primeiro capítulo "Jimmu Tennô - Jingô Kogô - Yoritomo", Azevedo retoma a visão japonesa da própria História, o mito da criação do aquipêlago e do povo japonês a partir de uma brincadeira dos deuses. Diante do estreito entrelaçamento entre deuses e homens, Mito e História, fica evidente em que medida Azevedo se aproxima e também se diferencia dos viajantes europeus que na época visitavam o Japão. Azevedo não somente adota a fundamentação mítica da conquista das ilhas japonesas pelo povo originado do amor carnal dos deuses, toda a sua compreensão da cultura japonesa e identidade nacional parece ser regida fundamentalmente pela particularidade da soberania personificada pelo tennō. Ele explica detidamente que o Imperador japonês constitui uma genealogia divina ininterrompida até a Época moderna, iniciada por Kamu Yamato no Iwarehito, mais tarde chamado de Jimmu tennō, que teria falecido em 585 B.C. com mais de cem anos de idade. Essa origem nunca deveria ser esquecida 
quando se trata de compreender criticamente o Japão em vias de modernização, como o está fazendo Aluísio Azevedo:

“Assim, o atual Imperador, apesar da constituição parlamentar, apesar do seu prosaico uniforme de General de Divisão, é nada menos do que descendente direto da formosa Deusa do Sol e tem com certeza na augusta firbina centelhas das luzes cambiantes do ilustre diadema [de] seu antepassado; sacrossanta procedência donde lhe deriva indiscutível supremacia sobre todos os seus compatriotas terrestres e logo o direito absoluto de ser, nem só obedecido e cegamente respeitado por eles como soberano, mas adorado como divindade que é e como foram todos os seus consubstanciais antepassados." (Azevedo, 1984: 48-49)

Desse modo, o escritor brasileiro representa uma concepção dos fundamentos históricomitológicos do Japão que, por uma parte, se deve ao discurso oficial da época, mas que ao mesmo tempo está à frente de seu tempo - quando se leva em consideração que ainda durante a Segunda Guerra Mundial a antropóloga cultural estado-unidense Ruth Benedict teve que explicar detalhadamente aos seu conterrâneos esta particularidade da História japonesa, como fez no seu estudo The Chrysanthenum and the Sword (Benedict, 2005). Dantas comenta a percepção de uma cultura estrangeira por Azevedo como segue:

“Como vemos, na civilização japonesa nenhum abismo separa os deuses dos homens. Subir o curso da história é reencontrar as fontes mitológicas, de onde tudo decorre. [...] Não estranhemos então que duas crônicas antiquíssimas, o Kojiki e o Nihongi, com suas narrativas 
lendárias, seus deuses e heróis, ora virtuosos, ora briguentos ou rancorosos, mas criadores dos homens, do universo e das instituições, tenham servido de base, até o fim da Segunda Guerra Mundial, ao estudo das origens do Japão. Não estranhemos, por esta mesma razão, que Aluísio Azevedo retrace a história do Japão começando pela lenda." (Dantas, 1984b: 147-148)

O historiador Renato Ortiz estabelece uma analogia entre este fundamento mitológico da História e os fundamentos deterministas - entre eles os biológicos - do Naturalismo em Azevedo o no seu contexto inteletual:

“Não há nessas linhas nenhuma ironia. Aceita-se a versão mitológica como razoável. É provável que, para o autor, esse tipo de explicação possuísse uma força de persuasão equivalente a de outras interpretações que conhecia - como a de Sílvio Romero sobre o 'atraso brasileiro' e os ventos alíseos, ou de Nina Rodrigues e a subalternidade da raça negra. As justificativas forjadas pelos intelectuais brasileiros desta época não eram, como as transmitidas pelo Kojiki, propriamente mitológicas (no sentido estritamente antropológico), mas suas bases especulativas, o clima e a raça, eram tão implausíveis como os espíritos dos kami. No fundo, todo esse exercício discursivo, de brasileiros e de japoneses, possuía uma finalidade comum: dar conta, de maneira convincente, isto é, ideológica, isto é, da questão nacional." (Ortiz, 1997: 82-83) 
Ainda dentro da mesma temática, as afirmações de Azevedo sobre a relação entre shintoismo e buddhismo representam um primeiro exemplo esclarecedor da maneira como no seu texto se misturam inexatidões históricas, conscientes e insconscientes, com a sua percepção cultural, que supera as polaridades estarrecidas entre o próprio e o Outro. Mais uma vez, Azevedo não é o único no seu tempo que classifica o shintō incorretamente como 'religião de Estado', contrária ao Buddhismo, que seria a 'fé popular'. Esta oposição se originava do discurso oficial da era Meiji, que visava uma 'purificação' e 'japonização' da fé, para fortalecer a autonomia nacional e o nacionalismo (Dantas, 1984b: 154). ${ }^{7}$

Aqui, Azevedo se concentra nas dimensões transculturais da adoção do Buddhismo 'estrangeiro' e da sua 'reconciliação' com a fé 'nacional' shintoista. Através desse processo surgiram inter-relações complexas que possiblitaram, por exemplo, que em qualquer templo se realizassem rituais e orações da outra religião. Esta dinâmica, até hoje marcante e muitas vezes indevidamente simplificada, da cultura japonesa constitui um dos eixos centrais do interesse e da perspectiva de Aluísio Azevedo. ${ }^{8}$

O interesse pelas dinâmicas culturais da História japonesa não pode ser separado da dimensão literária do texto de Azevedo, que em nenhum momento esconde que contém esse impulso. Repetidas vezes Azevedo passa subitamente do relato aparentemente objetivo de eventos históricos para passagens narrativas muito vivas e

\footnotetext{
${ }^{7}$ Mais ou menos ao mesmo tempo, Lafcadio Hearn demostra grande sensibilidade ao tratar da essência do shintō, de tão difícil compreensão para os não-japoneses (Hearn 2005, especialmente o capítulo "The Household Shrine", 109141). Para Hearn, o shintoismo, devido à sua própria evolução histórica com a repetida integração de elementos estranhos de todo o continente asiático, não tinha como ser 'purificado': "The so-called 'Revival of Pure Shintō' —an effort, aided by Government, to restore the cult to its archaic simplicity, by divesting it of foreign characteristics, and especially of every sign or token of Buddhist origin - resulted only, so far as the avowed purpose was concerned, in the desctruction of priceless art, and in leaving the enigma of origins as complicated as before." (Hearn 2005: 110)

${ }^{8}$ Refiro-me à adoção consciente e ativa de elementos estrangeiros para apropriá-los ou 'ingeri-los' - no contexto de um estudo sobre um escritor brasileiro, é quase inevitável lembrar a metáfora da "antropofagia cultural", cunhada só algumas décadas mais tarde por Oswald de Andrade. Também entra nesse elogio do sincretismo religioso 'à japonesa', a forte crítica anticlerical de Aluísio Azevedo no contexto ocidental, caraterística das posições realistas e naturalistas em geral.
}

Brasiliana - Journal for Brazilian Studies. Vol. 2, n.2 (Nov 2013). ISSN 2245-4373. 
situadas no meio dos protagonistas e eventos. Por exemplo, conta a lenda da Imperadora Jing $\bar{u}-k \bar{g} g \bar{o}$, que governava o Japão entre 209-269 e que teria prolongado a sua gravidez durante três anos com a ajuda de uma pedra atada à sua barriga, para não ter que interromper a guerra contra a Coreia. Mas é, no nível histórico, justamente com esta campanha existosa que se inicia a influência chinesa no Japão, que se inicia o movimento transculturador que desde então não parou de marcar o país.

“Com esta vitória sobre a Coréia, entra no Japão a civilização chinesa, que no continente vizinho tinha já nessa época chegado ao seu máximo desenvolvimento, assim nas artes, como na literatura e na moral filosófica de Kang, conhecido no Ocidente pelo ilustre nome de Confúcius. [...] O Japão começa a ler e a escrever e não se forra a sacrifícios para aumentar o seu cabedal de luzes; acumula de garantias e favores os artistas, artesãos e operários de valia, que logo acodem avidamente da outra banda asiática de ferramenta em punho; chama a si cabalísticos astrólogos, facultativos e alquimistas, carregados de misteriosas retortas e alfarrábios." (Azevedo, 1984: 50)

O Japão também envia representantes para a China, que ali adquirem conhecimentos culturais e os trazem para casa. Esses mediadores são a força motriz de um golpe de Estado em 645, que leva às reformas Taika, um programa de reestruturação do país segundo o modelo chinês (Dantas, 1984b: 161). Este 'processo civilizatório' é ativamente propulsado pelos japoneses: professores e mestres da China e da Coreia são convidados, a escrita é adotada. Azevedo sublinha o papel ativo na recepção das influências externas 
e explica da sua própria perspectiva quais seriam as vantagens de participar da conformação de tais processos transculturadores:

“E o Japão acerta afinal o passo de seu progresso com o da China e entra, por diante, a caminhar tão seguro e firme, que em breve já não se contenta só com imitar os translados da mestra e vai por conta própria modificando alguns deles para melhor e mais bonito [...]." (Azevedo, 1984: 51-52)

Mais uma vez o escritor não resiste ao impulso literário e ilustra a sua tese com a lenda do Imperador chinês que procurava a vida eterna e soube que no Japão existiria uma planta cujo extrato a providenciaria. Enviou uma delegação de jovens ao Japão, dos quais se conta que somente teriam inventado a história para poder fugir do país. É esse o momento em que se inicia a imigração chinesa para o Japão, e com ela a História propriamente dita do país. Agora é que começam processos de mistura étnica que continuariam durante séculos:

“Fosse este ou não o ponto inicial da emigração chinesa, o fato é que só com esta começa verdadeiramente a história do Japão, como é também daí que começa e se vai estendendo pelos séculos novos a lenta e surda elaboração homogênica da raça, até conseguir ficar o seu tipo, depois da eterna luta etnológica, em que os elementos contrários se repelem entre si e os de afinidade eletiva se combinam e se fundem para sempre." (Azevedo, 1984: 53) 
Inevitavelmente surge a pergunta se Azevedo não estaria encarando o Japão implicitamente como um possível modelo para o Brasil. A população japonesa aparece aqui como resultado de séculos de 'mestiçagens', com o resultado de uma harmonia racial que - apesar ou justamente por causa dos elementos heterogêneos implicados? se apresenta como unidade. Paralelamente a esse processo, Azevedo acredita reconhecer no Japão uma identidade cultural íntegra, que por isso não negaria ser o produto de subsequentes e complexas misturas. O Japão parece ser a oposição ideal à confusão e conflitividade dos componentes étnicos e culturais do Brasil, como Azevedo as retratou nos seus romances.

Somente à margem, no segundo capítulo "Nobunaga - Taiko Sama - Ieiás", Azevedo contempla a chegada e presença dos portugueses como os primeiros europeus no Japão, que em 1542 pisaram solo japonês pela primeira vez de forma documentada. A História dessa relação marcada pelo comércio e pela missão cristã liderada por Francisco Xavier, posteriormente santificado, tem grande influência na evolução da História 'interna' do Japão, na vitória do daimyō Oda Nobunaga em 1573, que criou alianças temporárias com senhores feudais convertidos ao cristianismo e utilizou fortemente as armas de fogo adotadas dos portugueses, para transformar mais uma vez de maneira fundamental a ordem política e social do país e estabelecer um regime feudal, em rígido isolamento do estrangeiro. Mas Azevedo não aprofunda esse primeiro encontro entre europeus e japoneses, nem considera as fontes acessíveis - no que diz respeito aos arquivos e à língua - dos viajantes e missionários portugueses daquele tempo.

Em vez disso, o escritor descreve com intensidade a batalha decisiva na luta pelo poder entre Oda Nobunaga e Shibata Katsuie, assim como o suicídio honroso (seppuku) deste e dos seus súbditos depois da derrota. Então Azevedo passa a narrar as duas 
campanhas do "Vice-Imperador" e sucessor de Nobunaga, Toyotomi Hideyoshi, em 1592-95 e 1596-98, contra a Coreia e a China. De novo se constatam inexatidões históricas. Azevedo menciona, por exemplo, somente uma campanha e afirma que Hideyoshi tenha sido morto em 1598 no continente asiático, quando na verdade este não liderou pessoalmente a segunda campanha e faleceu no Japão, na fortaleza de Fushimi, a causa de uma isquemia cerebral ou de envenenamento. Mais uma vez é outra coisa que interessa ao escritor: Se Hideyoshi tivesse terminado a campanha, abandonada depois da sua morte, as relações entre o Japão e a Europa teriam se iniciado muito mais cedo. Mas do modo que os eventos occorreram, a História do país tomou outro rumo, isolado:

"Se Taiko-Sama conseguisse viver mais alguns anos, é natural que o Japão desde esse tempo entrasse em relações com o resto da Europa, pois isso fazia parte dos seus planos políticos herdados de Nobunaga, planos totalmente destruídos pelo homem fenomenal que os sucedeu." (Azevedo, 1984: 67-68)

Percebe-se que esta possibilidade não teria sido a melhor na visão de Azevedo. É muito eloquente como ele carateriza Ieyasu, o sucessor de Hideyoshi, e como este terminou as reformas iniciadas já por Nobunaga und Hideyoshi. Na compreensão de Azevedo, a nação e a cultura japonesas foram encontrando assim, na tranquilidade e segurança do isolamento e da ordem rígida que seguiu as numerosa fases de influência cultural externa, a sua própria forma e essência:

"A esse guerreiro, estadista e legislador a um tempo, caberá a glória de levar a efeito com um golpe decisivo o vasto plano de unificação feudal, 
concebido pelos seus dois grandes antecessores, e transubstanciar definitivamente a alma da nação inteira, moldando-a pelo harmoniosa complexidade do seu próprio talento original e criador." (Azevedo, 1984: 68)

Azevedo nunca afirma explicitamente o caráter de modelo que esse processo de unificação nacional, cultural e espiritual no Japão poderia ter para o Brasil - em nenhum momento do livro se refere à sua pátria -, mas esta perspectiva é bastante nítida. Azevedo carateriza o rígido isolamento durante o regime dos Tokugawa, e os regulamentos que entravam até na vida privada, nos corpos e no pensamento dos indivíduos, como vantajosos e propícios para a formação e o fortalecimento do ser japonês. Isto ficaria visível no florecimento e aperfeiçoamento das artes, em medida nunca antes vista, durante esse período de "renascimento japonês":

"A sua minuciosa e individualíssima lei deu logo au Japonês tal consistência e tal homogeneidade de caráter, que desde então a vida desse povo ressalta harmoniosa, inteiriça e original, como uma bela obra concebida e realizada de um só jato por um autor de gênio. Fechando ele ciosamente a sedutora pátria à curiosidade importuna e à grosseira cobiça dos ocidentais, foi que conseguiu fazer, nem só a unidade nacional, mas a glória artística do Japão." (Azevedo, 1984: 79)

E é portanto essa fase - marcada pelo ukiyo-e, as estampas coloridas sobre "vida e costumes do povo contemporâneo" -, que no conceito de Azevedo e das suas fontes europeias representa o "século de Hokusai e Utamaro", divulgado na Europa, como já 
se mencionou acima, por Edmond de Goncourt: "século em que o Japonés se constituiu em primeiro e mais poderoso artista decorador de todos os tempos." (Azevedo, 1984: 79)

\section{A modernização acelerada do Japão e a sua integração no sistema global}

Os capítulos 3, 4 e 5 de O Japão são dedicados à abertura do país, forçada pelo comandante Perry, à luta pelo poder daí desencadeada, à resultante abolição do shōgunato e ao estabelecimento do regime Meiji em torno à figura redefinida e fortalecida do tennō. Certamente é devido ao andamento confuso dos eventos e à proximidade temporal do momento da escrita que aqui Azevedo se limite a oferecer resumos. Ao mesmo tempo, porém, se trata de um período decisivo, em que se criam as condições fundamentais para a reconfiguração da nação e da sociedade, realizada a partir de 1868 (cf. Yamamura, 1996: 130).

De interesse aqui é o posicionamento de Aluísio Azevedo diante de acontecimentos históricos ainda atuais, cujas consequências ainda não tinham se configurado definitivamente no momento de sua estada no Japão. O que já se podia notar às vezes no âmbito do mito e do passado remoto, agora se manifesta de forma bem visível e decidida: Azevedo se solidariza com o Japão, que ele enxerga como vítima da agressão imperialista do Ocidente, que fora forçado a abrir a sua economia e a assinar tratados comerciais desfavoráveis, e que agora enfrenta o desafio de se integrar no sistema internacional. Esta situação pode facilmente ser aproximada da posição da jovem República Brasileira, criada somente em 1889 e confrontada com desafios semelhantes, sem que o texto de Azevedo estabeleça em momento algum essas analogias explicitamente.

Já durante a sua estada no Japão Azevedo pôde perceber claramente que o país estava apostando ofensivamente na via da modernização, para chegar à mesma altura 
dos poderes ocidentais. Esta percepção da evolução mais recente no país se combina repetidas vezes, na pena do escritor, com a dramatização dos momentos decisivos, dando vida aos personagens japoneses e convidando os leitores a simpatizar com eles, literarizando o processo histórico como luta pela sobrevivência de uma cultura ameaçada, sublinhando a força dessa identidade cultural por ele admirada. ${ }^{9}$

Azevedo defende abertamente a tese de que a chegada da marinha estadounidense foi a responsável exclusiva pelo início da guerra civil e revolução política no Japão, e como prova narra a 'pré-história' desse evento, cujo conhecimento seria imprescindível para poder compreender adequadamente os processos atuais (Azevedo, 1984: 89). O período do isolamento ordenado durante o regime dos Tokugawa teria possibilitado o florescimento singular tanto da cultura popular quanto das artes refinadas. Azevedo explica o sistema de apoio à produção artística - que diante da sua própria biografia de escritor deveria lhe parecer especialmente interessante. Porque os artistas japoneses teriam ignorado a pressão comercial ou de tempo, por não terem de viver da venda de suas obras, ao contrário poderiam se dedicar plenamente ao aperfeiçoamento das obras sob a proteção de um senhor feudal ou da corte imperial: "Como tinham vida garantida pelo príncipe a que serviam, e absolutamente despreocupada de necessidades materiais ou de ambições burguesas, trabalhavam sem impaciência, sem pressa de acabar, e só cuidosos da perfeição e requintado esmero." (Azevedo, 1984: 89)

Azevedo retrata o sistema econômico feudal como um mundo idealizado, onde ninguém aspiraa maximizar os lucros ou as capitalizações, mas gerava somente a riqueza necessária para a vida de todos, um mundo onde não reinavam as injustiças e os conflitos que marcavam a Europa nessa época:

\footnotetext{
${ }^{9}$ Azevedo não trata dos aspectos agressivos e violentos desse desenvolvimento acelerado do país. Um exemplo disso seria a Primeira Guerra Sino-Japonesa de 1894/95, que Azevedo omite por completo.
}

Brasiliana - Journal for Brazilian Studies. Vol. 2, n.2 (Nov 2013). ISSN 2245-4373. 
“O organismo político do Estado, como a própria economia do povo, achavam-se na mais sinérgica integridade de equilíbrio e força; neles se não acusava nenhum dos vírus que na Europa perturbaram e destruíram o sistema congênere; não havia questão religiosa; não haviam rivalidades dinásticas em luta, nem reivindicações filosóficas e populares contra o direito divino do Trono ou contra a autonomia civil e militar do Shogun; não haviam tendências igualitárias, transbordamento industrial dos limites que às competentes classes lhes traçavam as leis ieiasianas; a vida era fácil e simples, o país abundantes [...]. Não se acusava no corpo da nação o menor sinal dessa implacável moléstia oriunda dos Estados Unidos da América do Norte - a Febre do milhão, a cujo alucinador contágio nenhum país ocidental escapou até hoje [...]." (Azevedo, 1984: 90-91) ${ }^{10}$

Mas essa elevadíssima cultura japonesa, esse último reduto ainda não contaminado pelo modo de vida ocidental, agora ia se perdendo, ia ser extinguido pela modernização e a influência dos modelos culturais e da 'indústria cultural' europeia e norte-americana, com a sua arte comercializada e banalizada (Azevedo, 1984: 92). A versão oficial dizia que os Estado Unidos queriam estabelecer no Japão um ponto de escala para a conexão transpacífica com a China. Mas por trás estaria o desejo de se apoderar das riquezas que havia séculos supunha no país. Nesse momento decisivo Azevedo formula a sua crítica

\footnotetext{
${ }^{10}$ As contradições no posicionamento de Azevedo se explicam, em parte, através da crítica de Antonio Candido a respeito do romance $O$ cortiço, que construiria uma oposição entre brasileiros e imigrantes portugueses para encenar uma luta das nacionalidades, sem questionar o contexto do Brasil enquanto país ainda semi-colonial e da ordem social baseada na explotação econômica de ambos grupos (Candido 2004: 111). O mesmo vale para o contexto sócio-histórico da imagem idealizada do Japão aqui analisada e a situação real do país no século XIX.
}

Brasiliana - Journal for Brazilian Studies. Vol. 2, n.2 (Nov 2013). ISSN 2245-4373. 
da legitimação dos europeus e estado-unidenses de que a guerra civil japonesa já teria sido inevitável quando o Ocidente entrou no pais:

“Bem sei que os europeus e norte-americanos, naturalmente por decoro, não contam deste modo nos seus livros sobre o Japão os fatos que aqui vou narrando; dizem todos os autores, pelo menos os meus conhecidos, que a revolução existia em estado latente no Império Japonês e que a chegada do Comodoro Perry nada mais fizera do que precipitar-lhe os efeitos." (Azevedo, 1984: 94)

Assim, Azevedo se posiciona numa perspectiva que hoje se qualificaria como 'póscolonial', realizando uma escrita dirigida contra a manipulação intencionada da História no Ocidente e a exclusão das vozes japonesas:

“O país nunca tivera época de tão inteira paz e nunca vivera tão despreocupado de lutas. Esta é que é a verdade! Como se deram os sucessos vou eu dizê-lo francamente, porque entre o assaltante atrevido e a vítima scraficada, claro está que me coloco ao lado desta." (Azevedo, 1984: 94)

$\mathrm{Na}$ reonstrução histórico-literária desse momento por Azevedo, a ameaça de Perry aterroriza e paraliza o país e a população pacífica. Há uma divisão entre oportunistas e nacionalistas. O shōgun Iesada tenta ganhar tempo. Mas o tennō também entra em ação, abandona o seu isolamento celestial e exige a expulsão dos bárbaros estrangeiros. Com a 
sua versão da História, Azevedo pretende apresentar 'outra', a 'verdadeira' versão dos eventos em volta da abertura do Japão. Para tal fim, o escritor volta a se impor e narra como se estivesse do lado dos protagonistas, transformando-os às vezes em personagens literários. Em um momento, Azevedo dramatiza um diálogo entre tennō e shōgun, o seu primeiro encontro pessoal na História, discutindo a tática a seguir frente aos Estados Unidos:

“O Shogun expôs ao Micado a verdadeira situação do país e falou-lhe com franqueza; mostrou-lhe o perigo interno de armar os mais poderosos príncipes e disse-lhe quais eram as probabilidades negativas da resistência. Os americanos viriam fortes, e atrás deles estava a Europa inteira, a espreitar a situação, esperando o resultado da empresa para dela tirar partido!

- É preciso varrê-los! exclamou sinteticamente o Monarca.

- O melhor, insistiu o outro, seria aceitar uma conferência com Perry, fazer cara alegre e, por meios hábeis, com boa diplomacia, tratar de mistificá-lo, prometendo pouco e não dando nada...

- Isso é um paliativo que a ninguém aproveita!

- Mas que ganha tempo, durante o qual nos prepararíamos para a resistência e para a vitória neste momento impossíveis.

- Não engoliriam semelhante isca!

- Os ocidentais não conhecem absolutamente o mecanismo político do Japão... nem sequer sabem ao certo qual é o verdadeiro chefe do Estado; seria fácil por conseguinte engodá-los durante muito tempo, sem nada lhes ceder de positivo.

- Mas cedendo sempre... 
- Cedendo sombras de concessões... Que pode valer um simulacro de tratado, sem a assinatura do Imperador, e que...

Yeçada não conseguiu concluir a frase, porque Komei, ouvindo falar em tratado com os estrangeiros, teve um terrível assomo de cólera e bradou, com os lábios trêmulos e os olhos apopléticos:

- Um tratado?! Nunca! É preciso varrê-los! Se o Shogun, que é o Comandante das Forças, desobedecendo as minhas ordens, não der quanto antes providências para repelir os bárbaros, eu próprio chamarei às armas os príncipes japoneses e irei em pessoa comandá-los!" (Azevedo, 1984: 99-100)

Azevedo de deleita com a confusão geral no Ocidente diante da estrutura dual do poder no Japão, que fez com que os Estados Unidos inicialmente não soubessem da existência do tennō e acreditassem que o shōgun era o soberano do país. O imperador é retratado como figura simpática, mas alheia à situação real do país. Azevedo o faz pronunciar a intenção inimaginável de querer descer da esfera divina e liderar o seus guerreiros como ser humano. Shōgun Iesada, por sua parte, aparece como fraco: "O Shogun, coitado! Esse arfava cabisbaixo e tíbio, escondendo o rosto entre as duas mãos. Não sei se chorava." (Azevedo, 1984: 100)

Então entra em cena a figura que Azevedo considera central na constelação política do momento: Ii Kammon no Kami, agindo como representante do sucessor do Shōgun, ainda menor de idade:

"Vai a situação mudar de aspecto. Ii Kammon dispunha de todas as qualidades políticas que faltavam ao seu perplexo antecessor, audácia, 
energia, resolução, astúcia e sangue frio; talento não sei se tinha e espírito nativista posso afiançar que não." (Azevedo, 1984: 101)

Contra essas caraterísticas Azevedo defende o desejo do povo japonês de continuar vivendo em paz e à sua maneira, apoia o direito dos japoneses de autonomia cultural e integridade do caráter nacional. Nesse sentido ele compreende e justifica o assassinato de Ii Kammon por dezassete ronin fiéis ao Imperador, movidos por 'motivos morais', porque aquele teria sido um traidor da nação, visando secretamente a abertura e modernização do país.

Quando o partido dos nacionalistas e defensores de um fortalecimento do tennō acaba se impondo, para Azevedo isso significa o regresso do povo japonês às suas origens: "Volvia esse povo, como no princípio da sua formação étnica a agremiar-se em torno do centro espiritual da sua raça." (Azevedo, 1984:121)

\section{O espelho de Amaterasu: O Japão como fascínio exótico e modelo de identidade nacional}

O livro O Japão termina abruptamente e justamente no momento em que o Japão, como única saída para sobreviver enquanto nação soberana, se adianta à pressão externa e se abre 'voluntariamente' para o mundo ocidental. A partir desse momento o país começa a se apropriar dos logros e avanços da cultura ocidental e a se esforçar por ocupar um lugar próprio entre essas nações.

É decisivo na leitura do texto fragmentário de O Japão considerar a sua dimensão literária e a intenção político-cultural desse olhar brasileiro sobre a modernização japonesa, a integração consciente e ativa no sistema mundial durante a segunda metade do século XIX. Essa integração iria realizar mais uma história de sucesso ambivalente 
nas décadas posteriores à estada de Azevedo, atribuída ao talento e a visão política dos reformadores da época Meiji, à sua combinação harmoniosa do estrategismo político com a 'condição natural' da nação japonesa (Benedict, 2005: 79). Nesse contexto se deve ler, de modo implícito ou explícito, a busca consciente ou inconsciente de Azevedo por possíveis modelos, exemplos e orientações para o Brasil, no seu caminho do passado colonial, pelo presente neocolonial e rumo a um futuro verdadeiramente soberano. ${ }^{11}$

O seu texto contém dois polos significativos. Primeiro o fascínio, esteticamente motivado, pela cultura tão estranha e 'outra', que Azevedo compartia com muitos de seus contemporâneos e que pode ser retraçada através das suas obras de referência no Japonismo. Mas, como brasileiro, também se diferencia consideravelmente desses contemporâneos, na sua maioria europeus. Toda a sua reflexão sobre a cultura e sociedade japonesas, especialmente sobre o que se lhe apresenta como uma identidade nacional japonesa, tão admiravelmente unificada, fortificada e 'naturalizada', deve ser lida através da imagem negativa, sempre implícita, de uma problemática brasileira tão urgente e até hoje não resolvida de uma 'identidade nacional' sob o signo do passado colonial e das perspectivas para o futuro influenciadas, ou até ameaçadas, por forças externas. Nesse último ponto Azevedo faz coincidir o lugar brasileiro do autor com a realidade japonesa do seu objeto, excluindo os poderes e as fontes estado-unidenses e europeus. Isso se cristaliza quando ele se solidariza com a 'vítima do Ocidente' e aspira um conhecimento crítico a partir da estratégia japonesa da sobrevivência econômica e geopolítica no sistema mundial, sem por isso perder a sua soberania cultural.

Por essa razão, não comparto a crítica de Renato Ortiz, de que Azevedo generalizasse de forma negativa a História da civilização europeia, para enaltecer, de

\footnotetext{
${ }^{11}$ No âmbito da 'Teoria da Dependência', Vinhas de Queiroz (1973) elabora uma comparação análoga, diacrônica, entre a modernização japonesa na era Meiji e a imagem do Brasil como 'gigante adormecido' ou 'recém-acordado'. E - continuando essa analogia com o contexto americano - ainda um século mais tarde o antropólogo cultural Nestor García Canclini formula, já no subtítulo de seu famoso livro Culturas híbridas (1990), a pergunta eloquente pelas "Estrategias para entrar y salir de la Modernidad" para a América Latina.
}

Brasiliana - Journal for Brazilian Studies. Vol. 2, n.2 (Nov 2013). ISSN 2245-4373. 
forma igualmente generalizada, a civilização asiática, recaindo em uma espécie de Orientalismo anti-europeu (Ortiz, 1997: 87). O modo como Azevedo se aproxima da História e cultura do Japão é mais complexo, crítico e também contraditório. Azevedo não se interessa por outras culturas asiáticas ou pela Ásia como um todo, ele compreende o Japão como um fenômeno isolado. Parte disso é o seu silêncio relativo às aspirações imperialistas da nação em vias de modernização já antes da sua chegada no país, ou a limitação do contexto asiático àqueles aspectos que influem no processo da constituição cultural japonesa. Também é contraditória, portanto, a sua avaliação da presença portuguesa no Japão no século XVI, que umas vezes ele reduz, outras ele critica, mas que também retrata numa luz positiva em comparação com a missão cristã e com seus maiores concorrentes no país, os holandeses. É interessante observar que Azevedo não menciona nem atualiza a ligação histórica - étnica, linguística e cultura entre o Brasil e Portugal, para aproximar de alguma maneira o objeto da sua reflexão (o Japão) à sua preocupação implícita (o Brasil).

Também pode estranhar como ele idealiza o domínio feudal dos Tokugawa nos séculos XVII a XIX, o que não se explica suficientemente com o seu entusiasmo artístico. Ao mesmo tempo Azevedo se mostra como admirador ambivalente da estratégia japonesa de integração global 'à mesma altura' com os poderes hegemônicos, e lamenta explicitamente a perda irreparável de um singular florecimento e refinamento cultural e artístico.

Com razão Ortiz supõe que a fase de transformação radical no Japão entre 1895-97, no âmbito das reformas Meiji, teria 'seduzido' Aluísio Azevedo a escrever esse livro. Consequentemente, para analisar os desenvolvimentos acompanhados no Japão, ele se fundamentaria na experiência de analisar e retratar, nos seus romances naturalistas, a 'alma brasileira' e a sua 'especifidade mestiça' (Ortiz, 1997: 80). Este aspecto nos conduz uma vez mais para a análise que Antonio Candido faz do Naturalismo em O cortiço. Ali, 
segundo Candido, as forças exploradoras externas e centripetais se imporiam às forças centrifugais constitutivas da sociedade brasileira. Na perspectiva de Azevedo, no Brasil não há saída da fragmentariedade e do atraso social:

“A perspectiva naturalista ajuda a compreender o mecanismo d'O cortiço, porque o mecanismo do cortiço nele descrito é regido por um determinismo estrito, que mostra a natureza (meio) condicionando o grupo (raça) e ambos definindo as relações humanas na habitação coletiva. Mas esta força determinante de fora para dentro é contrabalançada e compensada por uma força que atua de dentro para fora: o mecanismo de exploração do português, que rompe as contingências e, a partir do cortiço, domina a raça e supera o meio." (Candido, 2004: 119)

Ao contrário disso, no Japão a situação parece se inverter: o povo originado do mito e ordenado em torno ao tennō representa uma harmonia mediada através da natureza do arquipêlago e historicamente formada, uma nação 'saudável', que é perturbada desde fora, pela pressão centrifugal do sistema global e forçada ao movimento prejudicial e fatal. Tendo em vista a integridade da cultura admirada, definida pela sua condição na era dos Tokugawa, os eventos se apresentam a Azevedo tão inevitáveis e determinados como os esforços dos personagens nos seus romances. Também aponta nessa direção o título possível do livro, "Agonia de uma raça".

Focalizando o contraste marcante entre a heterogeneidade étnica do Brasil e a aparente homogeneidade étnica japonesa, Aluísio Azevedo se deixa seduzir pela mitologia japonesa - na sua leitura fundamentalista da era Meiji. Ele não enxerga e 
provavelmente não está interessado em enxergar a natureza artificial do mito da 'raça japonesa'm construído para encobrir a história das sucessivas imigrações e miscigenações que levaram á constituição do povo japonês até o momento de seu isolamento quase que absoluto. Fica evidente que a intenção principal de Aluísio Azevedo, ao escrever o livro sobre o Japão, não foi um retrato historicamente correto e adequado do país. A sua força motriz parece ter sido, em grande parte, o forte contraste, a quase que inversão da situação histórica interna e externa do Japão em comparação com o Brasil.

Assim como Candido constata no romance naturalista de Azevedo a necessidade de interpor a nação brasileira como mediadora entre a percepção da realidade social e a sua representação concreta conforme o programa literário (Candido, 2004: 128), no confronto de Azevedo com a cultura japonesa se reconhece, como num espelho, a reflexão do destino de uma identidade nacional dentro de outra. Dantas aponta para esse efeito de espelhamento na tentativa de Azevedo de interpretar o Japão:

“Esta é um preocupação que Aluísio Azevedo traz de sua reflexão sobre o Brasil. O problema é análogo. Evitar a imitação ('macaqueação') dos costumes estrangeiros e afirmar a especificidade de um 'povo'. Com uma diferença, porém: o Brasil contava apenas com um futuro incerto. Povo 'sem tradição', ou melhor, com um passado que desencanta as elites brasileiras, ele somente ultrapassaria suas limitações no momento em que uma nova amálgama das raças produzisse um tipo mestiço capaz de suplantar os atavismos anteriores. Em relação à incerteza brasileira o Japão surge assim como um contraponto promissor. Composto de uma unidade racial - resultado de 'uma lenta e surda elaboração homogênica da raça ate conseguir fixar o seu tipo' -, isolado 
dos contatos externos, ele seria ainda dotado de uma tradição ancestral. A questão nacional se identifica, assim, à reafirmação dos costumes e ao combate as forças exógenas." (Dantas, 1984b: 91)

Perante as forças determinantes do mundo moderno no início do século XX, a transformação era pressuposto inprescindível da Modernidade. O Brasil na sua recente condição póscolonial e nacional, estava especialmente exposto a e vulnerável nesses processos modernizadores, enfrentando dificuldades internas particulares devidas à sua composição étnica e social. Nesse contexto, as 'estratégias' de modernização do Japão também no sentido cunhado por García Canclini -, muito centralizadas e impostas com veemência e violência pelo Estado, constituíam um exemplo no extremo oposto da escala internacional. Evidentemente, Azevedo não poderia acreditar na possibilidade do Brasil imitar ou seguir a trajetória do Japão, mas parece provável que através do contraste ele buscasse - na mistura da escrita literária com a histórica - uma inspiração, um meio-termo viável para o Brasil superar as suas conflitividades internas e se opor à pressão externa da modernização, sem por isso perder a sua identidade nacional, baseada na variedade sóciocultural.

\section{Notas finais}

Amaterasu-o-mi-kami é a Deusa do Sol e da Luz. Do ventre dela se originou a humanidade - nasceram os japoneses e o tennō. O seu símbolo é o espelho de bronce com o qual foi levada a sair da cova, onde se tinha retraído por raiva do irmão Susanoono-Mikoto, deixando o mundo na escuridão: dentro desse espelho divino, Yata-nokagami, Amaterasu continua vivendo. Ele é guardado e venerado até hoje no templo shintoista de Ise como o centro da nação japonesa. Metaforicamente, Aluísio Azevedo 
posicionou esse espelho de tal maneira que refletisse a sua pátria brasileira - que no texto não é mencionada nenhuma vez - viabilizando assim o contraste produtivo com a cultura e identidade japonesa, visualizando uma nova compreensão do Brasil e lançando uma luz iluminadora sobre o seu lugar na Modernidade e no sistema global. Simultaneamente, o seu olhar 'brasileiro' transmite aspectos da cultura e História do Japão que na visão e representação geral do país nem sempre recebem o destaque merecido: a sua versatilidade, o seu caráter aberto e ao mesmo tempo fechado - as suas estratégias de sobrevivência na e através da transformação.

\section{Bibliografia:}

Azevedo, Aluísio. O mulato. São Paulo: Livraria Martins, 1970.

Azevedo, Aluísio. O cortiço. São Paulo: Editora Moderna, 1983.

Azevedo, Aluísio. O Japão. Apresentação e comentários por Luiz Dantas. São Paulo: Kempf, 1984.

Benedict, Ruth: The Chrysanthemum and the Sword. Patterns of Japanese Culture. Boston/New York: Mariner Books, 2005.

Candido, Antonio. "Introdução". In: Formação da literatura brasileira. Momentos decisivos. 2 vol. 6 $6^{\mathrm{a}}$ ed. Belo Horizonte/Rio de Janeiro: Editora Itatiaia, 2000, pp. 23-40.

Candido, Antonio. "De cortiço a cortiço". In: O discurso e a cidade. $3^{\underline{a}}$ ed. São Paulo/Rio de Janeiro: Duas Cidades/Ouro sobre Azul, 2004, pp. 105-132.

Dalcastagnè, Regina. "Da senzala ao cortiço - história e literatura em Aluísio Azevedo e João Ubaldo Ribeiro". In: Revista Brasileira de História 21/42, 2001, pp. 483-494.

Dantas, Luiz. “Apresentação / Introdução”. In: Aluísio Azevedo: O Japão. Apresentação e comentários por Luiz Dantas. São Paulo: Kempf, 1984a, pp. 7-46. 
Dantas, Luiz. "Chaves para compreender O Japão de Aluísio Azevedo": In: Aluísio Azevedo: O Japão. Apresentação e comentários por Luiz Dantas. São Paulo: Kempf, 1984b, pp. 143-229.

Feldmann, Helmut. Venceslau de Morais e o Japão. Macau: Instituto Cultural de Macau/Comissão Territorial para as Comemorações dos Descobrimentos Portugueses, 1992.

França Suzuki, Ana. O jardim japonês. Rio de Janeiro: Record, 1986.

García Canclini, Nestor. Culturas híbridas. Estrategias para entrar y salir de la modernidad. México: Grijalbo/Consejo Nacional para la Cultura y las Artes, 1990.

Handa, Tomoo. O imigrante japones. História de sua vida no Brasil. São Paulo: T.A. Queiroz/Centro de Estudos Nipo-Brasileiros, 1987.

Hearn, Lafcadio. Glimpses of Unfamiliar Japan. New York: Cosimo Classics, 2005.

Honda-Hasegawa, Laura. Sonhos bloqueados. São Paulo: Estação Liberdade, 1991.

Ishi, Angelo. "Searching for Home, Wealth, Pride, and 'Class': Japanese Brazilians in the 'Land of Yen'”. In: Jeffrey Lesser (org.). Searching for Home Abroad. Japanese Brazilians and Transnationalism. Durham: Duke University Press, 2003, pp. 75-102.

Mérian, Jean-Yves. Aluísio Azevedo. Vida e obra (1857-1913). O verdadeiro Brasil do século XIX. Rio de Janeiro: Espaço e Tempo/Ministério da Cultura/Instituto Nacional do Livro, 1988.

Moares, Wenceslau de. Dai-Nippon. O Grande Japão. 3a ed. Lisboa: Parceria A.M. Pereira Ldta, 1972.

Ninomiya, Masato . “O centenário do Tratado de Amizade, Comércio e Navegação entre Brasil e Japão". In: Revista USP 28, 1995/96, pp. 245-250.

Nakasato, Óscar. Nihonjin. São Paulo: Benvirá, 2011.

Ortiz, Renato. “Aluísio de Azevedo e o Japão. Uma apreciação crítica". In: Revista de Sociologia da USP IX/2, 1997, pp. 79-95. 
Saito, Hiroshi (org.). A presença japonesa no Brasil. São Paulo: T.A. Queiroz/Edusp, 1980.

Sam, Sílvio. Sonhos que de cá segui. São Paulo: Ysayama Editora, 1997.

Sasaki, Elisa. “A imigração para o Japão". In: Estudos Avançados XX/57, 2006, pp. 99-117.

Sociedade Brasileira de Cultura Japonesa/Comissão de Elaboração da História dos 80 anos da Imigração Japonesa no Brasil (orgs.). Uma epopéia moderna: 80 anos de imigração japonesa no Brasil. São Paulo: HUCITEC/Sociedade Brasileira de Cultura Japonesa, 1992.

Tsuda, Takeyuki (Gaku). "Homeland-less Abroad: Transnational Liminality, Social Alienation, and Personal Malaise". In: Jeffrey Lesser (org.): Searching for Home Abroad. Japanese Brazilians and Transnationalism. Durham: Duke University Press, 2003, pp. 121162.

Tucci Carneiro, Maria Luiza / Takeuchi, Márcia Yumi (orgs.). Imigrantes japoneses no Brasil: trajetória, imaginário e memória. São Paulo: Edusp, 2010.

Vinhas de Queiroz, Maurício. "Brasil e Japão: analogias e contrastes históricos". In: Debate e crítica I/1, 1973, pp. 95-122.

Yamamura, Roberto Jimmy Hideki. "O estabelecimento das relações Brasil-Japão no século XIX". In: Textos de História IV/1, 1996, pp. 125-148.

Yamashita, Karen Tei, Circle K Cycles. Minneapolis: Coffee House Press, 2001. 